\title{
Altered beta diversity in post-agricultural woodlands: two hypotheses and the role of scale
}

\author{
Emily Grman, John L. Orrock, Christopher W. Habeck, Joseph A. Ledvina and Lars A. Brudvig \\ E. Grman (grmanemi@msu.edu), C. W. Habeck, J. A. Ledvina and L. A. Brudvig, Dept of Plant Biology, Michigan State Univ., Plant Biology \\ Laboratories, 612 Wilson Road, Room 368, East Lansing, MI 48824-1312, USA. CWH also at: Dept of Biology, Kutztown Univ., PO Box 730, \\ Kutztown, PA 19530, USA. - J. L. Orrock, Dept of Zoology, 430 Lincoln Dr., Univ. of Wisconsin, Madison, WI 53706, USA.
}

\begin{abstract}
Agricultural land use commonly leaves a persistent signature on the ecosystems that develop after agricultural abandonment. This agricultural legacy limits the biodiversity supported by post-agricultural habitats compared to remnant habitats that have never been used for agriculture. In particular, beta diversity (variation in community composition across space) at both large and small spatial scales can differ between post-agricultural and remnant habitats, but we do not understand the mechanisms driving these differences. We surveyed plant communities at 29 pairs of post-agricultural and remnant longleaf pine woodlands (58 total woodlands) to test for patterns consistent with two hypothesized mechanisms for why post-agricultural ecosystems support altered beta diversity. 1) Post-agricultural sites support different levels of underlying environmental heterogeneity than remnants. 2) Establishment of species associated with remnant habitats into postagricultural woodlands is limited by dispersal and/or environmental conditions. We found no support for the environmental heterogeneity hypothesis and strong support for the idea that species establishment limits reassembling communities. Our results revealed a novel and important nuance to the establishment limitation hypothesis: spatially constrained, but not completely prevented, re-establishment of remnant-associated species in post-agricultural woodlands increased within-site beta diversity, contrary to results at larger among-site (landscape) scales. Our use of a powerful paired-site design permits these insights into how agriculture and abandonment affect beta diversity at two spatial scales, highlighting the prominent influence of edges even a half century after agricultural abandonment. The importance of constrained species establishment during ecosystem recovery, and its scale-dependent effect, could provide valuable guidance to enhance the utility of post-agricultural habitats for biodiversity conservation.
\end{abstract}

Widespread human alteration of ecosystems is a dominant aspect of global change and a major threat to biodiversity conservation (Wilcove et al. 1998, Sala et al. 2000). Land abandoned from agriculture is also a large and growing component of many landscapes (Dobson et al. 1997, Flinn and Vellend 2005) and represents an opportunity for conserving biodiversity as ecosystems recover from agricultural disturbances (Cramer et al. 2008). However, postagricultural ecosystems often support altered communities or reduced biodiversity for decades or centuries following abandonment (Flinn and Vellend 2005). In particular, postagricultural communities can exhibit reduced beta diversity (i.e. reduced variability in community composition across space) relative to remnant communities lacking agricultural histories (Polley et al. 2005, Vellend et al. 2007, Baeten et al. 2010). Beta diversity loss following agricultural use and land abandonment may contribute to growing concerns about biotic homogenization (Olden and Rooney 2006), where communities become increasingly similar within localities and across regions, threatening biodiversity conservation. Several studies have documented that post-agricultural lands may have lower beta diversity, but testing whether agriculture decreases beta diversity, and if so by which mechanisms, has remained difficult. Simultaneously, post-agricultural ecosystems present unique opportunities to study the mechanisms shaping community assembly and the development of beta diversity (Flinn and Vellend 2005).

Understanding the effects of agricultural legacies on beta diversity is inherently a multi-scale endeavor for two reasons. First, beta diversity exists at multiple spatial scales and different ecological processes can influence beta diversity at various spatial scales (Barton et al. 2013). Second, the effects of past agriculture may vary across scales (Questad et al. 2011). Agricultural legacies can reduce beta diversity among disparate sites (Vellend et al. 2007, Baeten et al. 2010, Questad et al. 2011), but can lead to higher or lower within-site beta diversity (Martin et al. 2005, Polley et al. 2005). As a result, it is imperative to focus analyses of beta diversity at two different scales: among sites and within sites. Although beta diversity is frequently considered at larger, among-patch scales (Vellend et al. 2007), patterns of beta diversity at smaller, within-site scales are also important elements of landscape heterogeneity, which contribute to biodiversity at the landscape scale (Veech et al. 2002, 
Kraft et al. 2011) and may represent an important target for conservation (Martin et al. 2005, Questad et al. 2011). Furthermore, the discrepancy of agriculture's effects at large vs small scales raises questions about whether the community assembly mechanisms that drive the development of beta diversity operate similarly across spatial scales (Barton et al. 2013).

Here, we consider two hypothesized mechanisms that could cause a history of agriculture to decrease beta diversity and evaluate the support for each hypothesis at large and small spatial scales (i.e. among-site and within-site beta diversity). Both mechanisms can involve species sorting, a community assembly processes where community composition is determined by species' responses to abiotic gradients, where species persist only in environments to which they are well suited. This results in consistent relationships between species and the environment (also termed 'structured' beta diversity by Vellend et al. 2007, Harrison et al. 2011). Here, we use 'stronger species sorting' to mean tighter and more consistent relationships between community composition and environmental conditions.

First, beta diversity might be altered in post-agricultural ecosystems because of differences in the amount of environmental heterogeneity. Agriculture can alter the spatial distribution of soil properties, either increasing or decreasing heterogeneity in soil nutrients, moisture, $\mathrm{pH}$, or organic matter (Robertson et al. 1993, Fraterrigo et al. 2005, Flinn and Marks 2007). This pattern could occur at large spatial scales, as farmers apply fertilizer only in sites where soils are relatively infertile, reducing heterogeneity, or as different farmers employ different agricultural practices, increasing heterogeneity among sites (Fraterrigo et al. 2005). An effect of agriculture could also occur at smaller, within-site scales, as fertilization may be more or less intense at field edges, increasing heterogeneity, or tillage could promote spatial mixing of soils, reducing heterogeneity (Fraterrigo et al. 2005). As a result, beta diversity might be higher or lower in postagricultural communities compared to remnants, depending on whether agriculture increased or decreased environmental heterogeneity and over which scales this occurred.

Second, beta diversity may be altered in post-agricultural sites because of limitations to species establishment (Vellend et al. 2007). Dispersal limitation or environmental conditions may limit establishment and thereby constrain species sorting that would otherwise happen along gradients in postagricultural sites. This process would reduce beta diversity if establishment limitation operated similarly across space e.g. by consistently constraining establishment to a common set of species (Vellend et al. 2007). Agriculture can leave lasting and significant legacies on environmental conditions including soil nutrients, the litter layer, and the abundance of trees (Flinn and Vellend 2005, McLauchlan 2006, Flinn and Marks 2007, Brudvig et al. 2013), all of which could affect species establishment in post-agricultural areas. However, establishment limitation may not occur uniformly across space and, as a result, partial establishment (e.g. near edges) may actually increase beta diversity in post-agricultral habitats. For example, dispersal limitation that enables species to disperse only to nearby, but not distant, post-agricultural localities, would increase beta diversity across those localities. Thus, establishment limitation may increase or decrease beta diversity in post-agricultural ecosystems, depending on whether species establishment occurs consistently or inconsistently across space.

We evaluated each hypothesis at two spatial scales, considering within- and among-site beta diversity in post-agricultural plant communities. We used pairs of adjacent woodlands that are similar except in their histories of agricultural land use. This paired sampling design minimizes false signals of land-use legacies caused by non-random land-use decisions (e.g. a greater propensity for productive sites to be used for agriculture; Flinn and Vellend 2005, Brudvig et al. 2013). Therefore, we can more directly address the question of whether agriculture reduces beta diversity in communities that later develop than previous studies which have been unable to employ a paired design. We first asked whether beta diversity differs between post-agricultural and remnant woodlands, either among or within sites. We then asked whether differences in beta diversity could be driven by differences in 1) environmental heterogeneity and 2) limits on species establishment and recolonization of post-agricultural woodlands.

\section{Material and methods}

\section{Study system and sampling}

The U.S. Dept of Energy's Savannah River Site, a National Environmental Research Park near Aiken, SC, provides an ideal study system for identifying the mechanisms that structure beta diversity in post-agricultural and remnant ecosystems. Currently, much of the site is former row-crop agricultural land, planted to pine plantation in the early 1950s (largely longleaf pine Pinus palustris, but also loblolly Pinus taeda or slash pine Pinus elliottii). Embedded within this matrix of post-agricultural woodland, remnant patches of longleaf pine woodland persist. Using aerial photos taken in 1951, we confirmed that these remnant woodlands had no recent agricultural history. Importantly, adjacent remnant and post-agricultural woodlands have no obvious environmental differences such as steep slopes, rocky soils, soil series, or other features that would have resulted in nonrandom land-use decisions by farmers. Although fire suppression and selective logging of longleaf pines have resulted in a hardwood-dominated closed canopy in remnants, they support a diverse understory plant community characteristic of longleaf pine woodland. Even decades after afforestation, agricultural legacies are evident: post-agricultural woodlands support a different understory community and different environmental conditions than remnant woodlands (Fig. 1; Brudvig et al. 2013).

We selected 29 sites, each spanning a boundary between post-agricultural and remnant woodland. All sites occurred on relatively sandy, well-drained upland soils with shallow slopes. At each site, we set up two pairs of contiguous 1-ha square plots, one plot in each pair in remnant woodland and the other plot in post-agricultural woodland. Each 1-ha plot was wholly contained within a single remnant woodland or historical agricultural field (i.e. no 1-ha plot spanned the historical land-use boundary). This use of paired plots allows us to control for non-random past land-use decisions (Flinn 


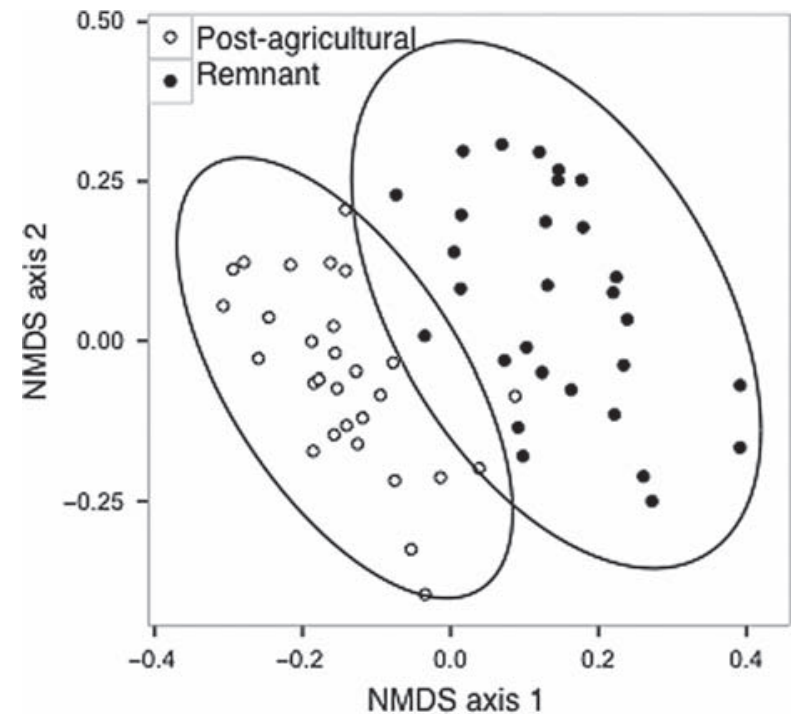

Figure 1. Nonmetric multidimensional scaling ordination of understory plant communities in post-agricultural (open) and remnant (filled) woodlands. Ellipses represent 95\% CI; ellipses of approximately the same size indicate nearly equivalent among-site beta diversity.

and Vellend 2005). Distances among post-agricultural plots ranged from $0.128-27.923 \mathrm{~km}$ and distances among remnant plots ranged from $0.297-27.749 \mathrm{~km}$. Beginning at, and perpendicular to, the remnant/post-agricultural boundary, we extended a $100-\mathrm{m}$ transect into each plot (yielding four $100-\mathrm{m}$ transects per site, two in post-agricultural and two in remnant woodland). The beginning point of each transect was directly adjacent to its paired transect, so all sampled post-agricultural communities were within $100 \mathrm{~m}$ of a remnant patch. We set up ten $10 \times 10$-m subplots along each transect. In each subplot, we collected species presence absence data in August-October 2010 by identifying all vascular plant species less than $2.5 \mathrm{~cm}$ diameter at breast height using Radford et al. (1968), except for Dichanthelium and Pityopsis, for which we used Weakley (2008). We also counted the number of living trees and measured live tree basal area. We used a concave spherical densiometer to measure percent canopy closure from the center of each subplot (mean of four measurement orientations). We also measured the depth of the woodland floor (leaf litter and duff), an important determinant of species diversity in this system (Hiers et al. 2007), just outside the four corners of a $1 \times 1$-m quadrat in one corner of each $10 \times 10$-m subplot. We collected and composited eight soil cores around the perimeter of the $1 \times 1-\mathrm{m}$ quadrat and analyzed the samples for soil moisture, a determinant of diversity and composition in longleaf pine understories (Kirkman et al. 2001, Peet 2006). We measured soil moisture on sieved, saturated samples following Brudvig and Damschen (2011) as an index of the soils' ability to retain moisture. Soils were also analyzed for soil $\mathrm{pH}$, phosphorus (Mehlich III), inorganic nitrogen (1 $\mathrm{N} \mathrm{KCl}$ cadmium reduction), and soil organic matter (loss-on-ignition; Brookside Laboratories, New Knoxville, $\mathrm{OH})$, which are important for plant communities and often impacted by agricultural legacies (Flinn and Vellend 2005). Post-agricultural soils tended to have higher phosphorus, and lower nitrogen, organic matter, moisture, and potassium than remnant soils; $\mathrm{pH}$ and other micronutrients did not differ between land-use histories (Brudvig et al. 2013). For additional details on sites, methods, and plant communities, see Brudvig et al. (2013).

\section{Statistical analysis}

To investigate the effects of agricultural legacies on beta diversity and test our two causal hypotheses, we conducted analyses at two spatial scales: among and within sites.

Beta diversity: to assess beta diversity, we calculated the multivariate distance of each community composition to the group centroid (Anderson et al. 2006). For the amongsites analysis, all species in a woodland (pooling across the two transects of the same land-use history) comprised a single local community; the groups were remnant or postagricultural communities (29 communities in each of the two groups). Within sites, each $10 \times 10$-m plot was considered a local community; the groups (regions) were the transects (10 communities in each of 116 groups).

We used Jaccard dissimilarities for all analyses of community composition at both scales because it is appropriate for our dataset and its properties are relatively well understood. While Jaccard dissimilarity may be biased by differences in alpha (local) species richness between groups (Chase et al. 2011), this was not a problem in our dataset, as richness per $10 \times 10-\mathrm{m}$ plot and $10 \times 100-\mathrm{m}$ transect is similar in remnant and post-agricultural woodlands (Brudvig et al. 2013). Furthermore, a recently proposed alternative, Raup-Crick dissimilarity, may have undesirable properties under some circumstances (e.g. when alpha is small or large relative to regional richness; Chase et al. 2011), which are only beginning to be investigated quantitatively (Germain et al. 2013); we wished to avoid these potential issues.

Environmental heterogeneity: to test our hypothesis that differences in beta diversity between remnant and postagricultural woodlands are driven by differences in environmental heterogeneity, we measured heterogeneity among and within sites and compared heterogeneity between postagricultural and remnant woodlands.

Among sites, we calculated the distance to group centroid of the five soil variables $(\mathrm{pH}$, phosphorus, nitrogen, water holding capacity, and organic matter) using Euclidean dissimilarities and tested for differences between postagricultural and remnant woodlands with a permutation test (Anderson et al. 2006). We tested for differences in heterogeneity of tree abundance (canopy cover, tree density, and tree basal area) similarly. We used Levene's test to test for differences in heterogeneity of woodland floor depth.

Within sites, we calculated the mean subplot multivariate distance to centroid for each transect separately for soils and trees; for woodland floor depth we calculated the transect coefficient of variation $(\mathrm{CV})$. We then averaged transectlevel heterogeneity values across the two replicate transects at each site and tested for differences between post-agricultural and remnant woodlands with paired-sample t-tests.

Establishment limitation: to test our hypothesis that remnant and post-agricultural communities differ in beta diversity because of establishment limitation, we used two 
approaches. To compare the strength of species sorting between post-agricultural and remnant forests, we conducted a two-step analysis at each spatial scale to assess the degree to which variation in communities is linked to variation in the environment. A weaker association between the community and the environment (weaker species sorting) could indicate a uniform dispersal limitation (Vellend et al. 2007). First, we reduced the number of environmental variables from nine to three. To do this, we conducted a principal components analysis (PCA) of the five soil variables (log-transformed when necessary to reduce the impact of outliers) and extracted the first axis. We performed a similar analysis on square-root or arcsin-transformed tree abundance variables. We used woodland floor depth as the third environmental variable. Second, to measure the association between the community and the environment, we conducted a distance-based redundancy analysis (dbRDA; Legendre and Anderson 1999) with soil, trees, and woodland floor depth as constraining variables. Although this analysis does not explicitly compare beta diversity between post-agricultural and remnant woodlands (variation in community composition among woodlands of the same land-use history), it compares the strength of a mechanism affecting community composition (species sorting) and therefore can help us understand potential drivers of beta diversity in each woodland type.

Among sites, we calculated the proportion of variation in community composition associated with the environment (the strength of species-environment relationships) by summing the eigenvalues of the three constrained axes (analogous to variance explained) and dividing by the real total inertia (analogous to total variance in the community; Vellend et al. 2007).

Within sites, we conducted a similar dbRDA separately for each transect, additionally partialling out the effect of subplot distance along the transect to remove the influence of space and spatially-correlated environmental factors. We averaged the proportion of community variation associated with the environment across replicate transects at each site and used paired-sample t-tests to assess differences in the strength of species-environment relationships between remnant and post-agricultural woodlands.

Because of our paired-site study design, we could perform an additional analysis to test more directly for the role of establishment limitation at a smaller spatial scale. We tested whether post-agricultural communities (at the $10 \times 10-\mathrm{m}$ scale) became increasingly dissimilar from communities in the paired remnant site with increased spatial distance; this pattern would indicate that establishment limitation restricted species spread into post-agricultural woodlands. We furthermore tested whether any pattern of increasing compositional dissimilarity was linear or asymptotic by comparing fits based on AIC.

\section{Results}

Among-site beta diversity was 6\% greater among remnant than among post-agricultural woodlands, a nonsignificant trend in the expected direction $\left(\mathrm{F}_{1,56}=3.20, \mathrm{p}=0.08\right.$; Fig. 1). Consistent with this pattern of similar amongsite beta diversity between remnant and post-agricultural sites, species-environment relationships were of similar strength in both community types; among remnants 19\% of variation in community composition was associated with the environment, whereas $15 \%$ of the variation in community composition was associated with the environment in post-agricultural woodlands. This indicates relatively similar strength of establishment limitation between postagricultural and remnant woodlands. We observed differences in environmental heterogeneity, but in the opposite direction to the trend in differences in beta diversity. Although there were no differences in heterogeneity of woodland floor depth $\left(\mathrm{F}_{1,56}<0.1, \mathrm{p}=0.8\right)$ or tree abundance $\left(\mathrm{F}_{1,56}=\right.$ $0.6, \mathrm{p}=0.5)$, soils were more heterogeneous among postagricultural sites $\left(\mathrm{F}_{1,56}=20.1, \mathrm{p}=0.001\right)$, a pattern driven largely by variability in phosphorus (Supplementary material Appendix 1, Table A1). Together, these results indicate that among sites, differences in environmental heterogeneity did not cause differences in beta diversity, but that weak differences in establishment limitation were in the same direction as nonsignificant trends in beta diversity.

Within sites, we see different patterns. Post-agricultural woodlands had higher within-site beta diversity than remnants (Fig. 2; $\mathrm{t}_{28}=2.4, \mathrm{p}=0.03$ ). Consistent with the environmental heterogeneity hypothesis, soils, especially soil organic matter, were more variable within post-agricultural woodlands $\left(\mathrm{t}_{28}=3.0, \mathrm{p}=0.006\right.$; Supplementary material Appendix 1, Fig. A2 and A3). Even so, differences in withinsite beta diversity between post-agricultural and remnant woodlands remained significant $\left(\mathrm{X}^{2}{ }_{1}=4.6, \mathrm{p}=0.03\right)$ when using ANCOVA to statistically remove the nonsignificant effect of soil heterogeneity $\left(\mathrm{X}^{2}{ }_{1}<0.1, \mathrm{p}=0.8\right)$, indicating that greater soil heterogeneity in post-agricultural woodlands did not fully explain their greater within-site beta diversity. Tree abundance and woodland floor depth were similarly variable in post-agricultural and remnant woodlands $\left(\mathrm{t}_{28}=\right.$ $\left.0.2, \mathrm{p}=0.8 ; \mathrm{t}_{28}=1.4, \mathrm{p}=0.2\right)$. Counter to the establishment limitation hypothesis, the strength of species-environment relationships within sites did not differ between woodland types $\left(\mathrm{t}_{28}=-1.7, \mathrm{p}=0.1\right.$; Supplementary material Appendix 1, Fig. A1). However, community dissimilarity between post-agricultural and remnant subplots increased with distance from the remnant woodland (Fig. 3a; $\mathrm{X}_{9}^{2}=90.8$, $\mathrm{p}<0.001$ ), indicating limited spread of species from the remnants into the post-agricultural woodlands. Increases in compositional dissimilarity slowed with increasing distance (an asymptotic curve improved model fit by deltaAIC $=10.6$ over a linear relationship, and by deltaAIC $=24.7$ over a null relationship). While an asymptotic relationship between compositional dissimilarity and distance from the opposing land use history also occurred in remnant woodlands (Fig. 3b; $\mathrm{X}_{9}{ }_{9}=73.7, \mathrm{p}<0.001$; linear deltaAIC $=12.9$; null model deltaAIC $=13.0)$, the pattern was more consistent in the post-agricultural woodlands: excluding the edge subplots eliminated the pattern in remnants but not in post-agricultural woodlands $\left(\mathrm{X}^{2}{ }_{8}=0.1\right.$, $\mathrm{p}=0.7$ and $\mathrm{X}_{8}{ }_{8}=52.3, \mathrm{p}<0.001$, respectively). This spatial pattern may be the best explanation for greater beta diversity within the post-agricultural sites: when we omitted the edge subplots and calculated beta diversity among the remaining nine subplots, we found weaker (nonsignificant) support for differences in beta diversity between post-agricultural 


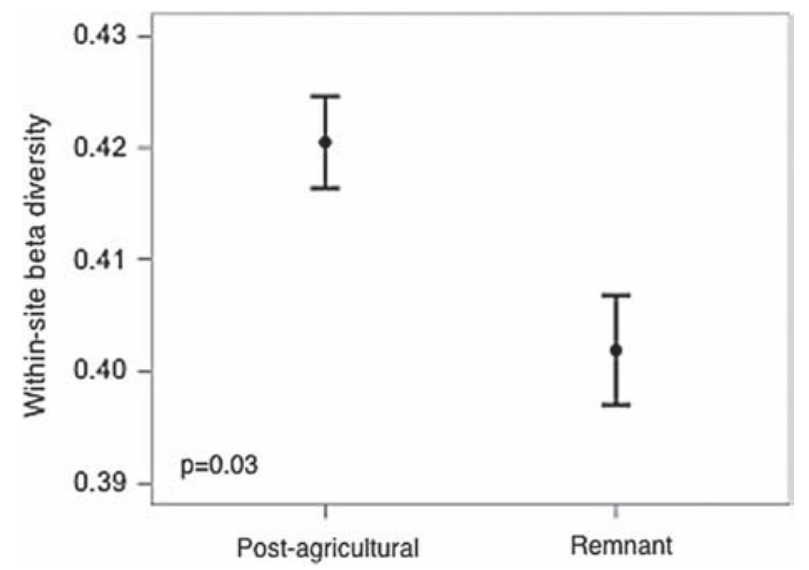

Figure 2. Within-site beta diversity of understory community was greater in post-agricultural woodlands than in remnant longleaf pine woodlands, calculated as mean distance to site centroid with Jaccard dissimilarities (means of 29 sites \pm SE).

and remnant woodlands $\left(\mathrm{t}_{28}=1.8, \mathrm{p}=0.09\right)$. This spatial pattern supports the establishment limitation hypothesis: at small scales, limited species spread from the remnants into post-agricultural woodlands increased beta diversity. Furthermore, establishment does not appear to be limited by the environmental factors we measured in the test for species sorting: $\mathrm{pH}$, phosphorus, nitrogen, water holding capacity, soil organic matter, tree canopy cover, tree density, tree basal area, and woodland floor depth.

\section{Discussion}

Understanding the effects of land-use legacies on plant communities, and the mechanisms driving those effects, may help elucidate the recovery of biodiversity in postagricultural habitats. Here, we find that at large spatial scales, among post-agricultural woodlands, beta diversity in understory plant communities was slightly but not substantially (6\%) lower than among remnant woodlands. This result was not driven by differences in local species pool sizes; species richness did not differ at $100 \mathrm{~m}^{2}$ or $1000 \mathrm{~m}^{2}$ (Brudvig et al. 2013). There were slightly more species observed across all remnant woodlands (265) than across all post-agricultural woodlands (248), perhaps explaining the marginally higher beta diversity in remnants.

This result of no large differences in among-site beta diversity between land-use histories is contrary to results found in other forest types where post-agricultural beta diversity is up to $56 \%$ lower (Vellend et al. 2007, Plue et al. 2008, Baeten et al. 2010). This difference could result from the younger age of the post-agricultural woodlands in this study (50-60 yr), compared with previous work ( $>100 \mathrm{yr}$; Vellend et al. 2007). However, the mechanisms explored here should cause beta diversity to increase with age, as more rare dispersal events accumulate and as species sort out along environmental gradients (Christensen and Peet 1984, Vellend et al. 2007, del Moral 2009, Foster et al. 2011, Alexander et al. 2012), so it seems unlikely that, with more time, these mechanisms would cause our post-agricultural woodlands (which were environmentally more heterogeneous) to develop lower
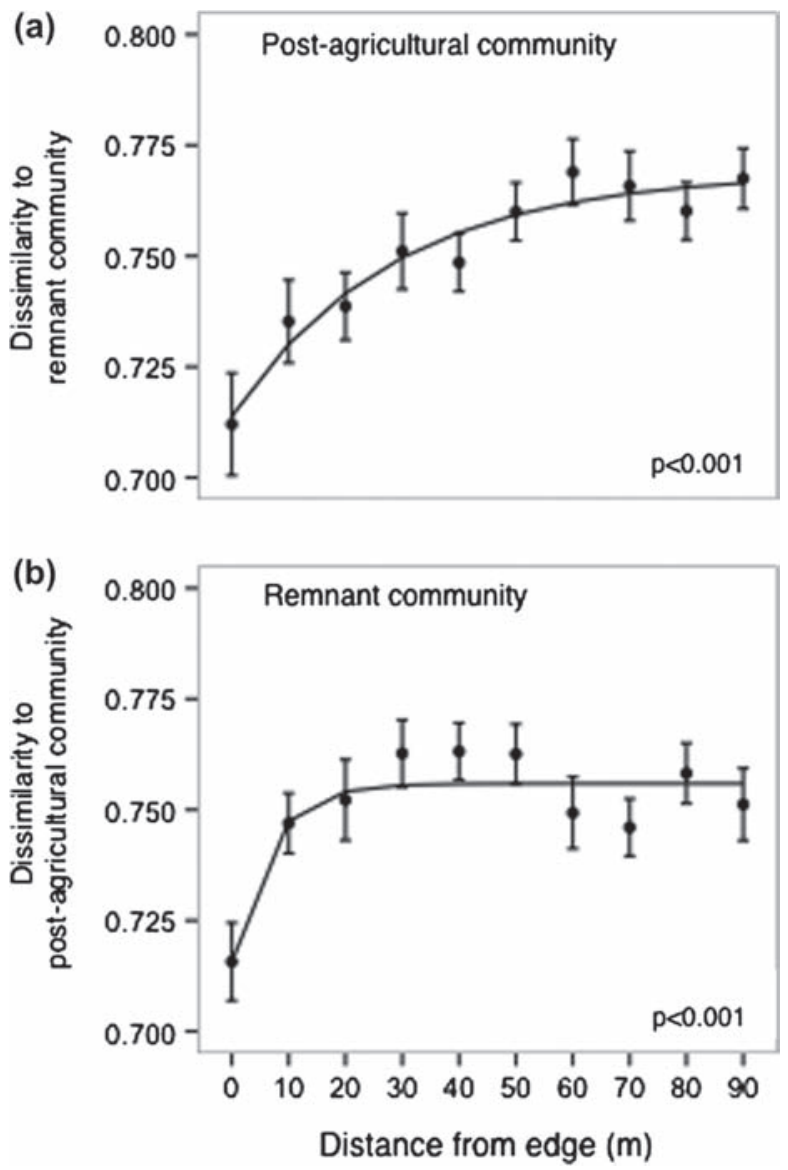

Figure 3. Distance from the boundary between land-use history types increased the Jaccard community dissimilarity between post-agricultural and remnant communities by (a) distance into post-agricultural woodlands (averaged across all remnant subplots), and (b) distance into remnant woodlands (averaged across all post-agricultural subplots) (means of 29 sites \pm SE; curves represent asymptotic fits, $\mathrm{p}<0.001$ compared to null model for post-agricultural and $\mathrm{p}=0.003$ for remnant communities).

beta diversity than remnants. Furthermore, observed differences in beta diversity between post-agricultural and remnant forests in Belgium remained consistent over $30 \mathrm{yr}$ (Baeten et al. 2010). Therefore woodland age is unlikely to explain our findings. Another possible explanation for different results between our and previous studies is that our post-agricultural woodlands were afforested intentionally and uniformly with native pine species. While tree planting might speed the development of the understory community, uniform planting would tend to decrease beta diversity of the understory, relative to a forest undergoing natural succession where tree size and identity is more heterogeneous. Therefore it seems unlikely that this management strategy is responsible for similar beta diversity in the understory of our post-agricultural and remnant woodlands. Finally, the different result between our and previous studies may also result from our use of a paired-site study design, which minimizes the signature of past land-use decisions. Non-random land-use decisions, where farmers chose suitable and similar land for agricultural use, could itself cause post-agricultural communities to be similar to each other (Flinn and Vellend 
2005, Brudvig et al. 2013). Thus, our study design enables us to more clearly investigate the causal influence of agriculture per se, as opposed to the coupled influences of agricultural decisions and post-agricultural legacies.

However, at small spatial scales, within sites, we find the opposite pattern: post-agricultural communities had higher beta diversity than remnant communities with no history of agricultural use. Within-site beta diversity differences were driven by community turnover near boundaries between post-agricultural and remnant habitat, illustrating how agricultural edges influence the spatial distributions of plant communities even many decades after agricultural abandonment and forest regrowth.

Establishment limitation reduces species richness and beta diversity among communities re-assembling in post-agricultural temperate forests (Flinn and Vellend 2005, Vellend et al. 2007, Plue et al. 2008, Baeten et al. 2010), and we hypothesized that they would act in our system as well. However, at the among-site scale, we found no support for reduced community species richness following agriculture (Brudvig et al. 2013) and only weak support for reduced beta diversity and reduced species-environment relationships among post-agricultural sites, suggesting that establishment does not strongly limit post-agricultural community reassembly at that scale. Furthermore, we did not detect stronger species-environment relationships among remnant than among post-agricultural woodlands, unlike work in northeastern North America and Europe (Vellend et al. 2007). This discrepancy between our study and others may have occurred because any establishment limitation slowing re-assembly in post-agricultural longleaf pine woodlands were overwhelmed by stronger community assembly constraints occurring uniformly in both community types. In particular, post-agricultural woodlands and remnant woodlands experienced equally strong fire suppression and consequently support deep litter and duff layers (Brudvig et al. 2013), which suppress species richness in longleaf pine woodlands (Hiers et al. 2007, Veldman et al. 2014). Another explanation for differences between these results and others is that our post-agricultural sites were all immediately adjacent to remnant sites. This proximity to propagule sources may have weakened dispersal limitation of many remnant species that recolonized post-agricultural woodlands, but our within-site results showing limited spread of many remnant species into post-agricultural plots suggest less support for this alternative.

In contrast, at the within-site scale, restricted species spread into post-agricultural woodlands resulted in more remnant-like communities in parts of post-agricultural woodlands adjacent to remnants. This increased the degree of local-scale variability in post-agricultural woodland community composition and increased within-site beta diversity. Limited species spread commonly restricts regeneration of remnant species in post-agricultural communities at comparable spatial scales (Matlack 1994, Singleton et al. 2001, Standish et al. 2007), even after centuries or millennia of recovery (Dupouey et al. 2002). However, to our knowledge, this mechanism has not yet been linked to an increase in beta diversity at these scales. While the strength of establishment limitation is known to decrease beta diversity (Chase 2007, Myers and Harms 2011), an opposing effect of establishment limitation on beta diversity is an important new finding because it provides a new mechanism capable of creating stark and unexpected contrasts in beta diversity.

Multiple mechanisms could have caused the establishment limitation we observed at small spatial scales. Dispersal limitation is an important constraint on assembling communities and may contribute to these patterns of limited species spread (Verheyen and Hermy 2001, Verheyen and Hermy 2004, Flinn and Vellend 2005). Seed addition in longleaf pine woodlands can increase small-scale understory species richness, indicating dispersal limitation (Myers and Harms 2009, 2011). Strong dispersal limitation could explain our result that nearby post-agricultural communities shared similar species; perhaps only good dispersers reached all localities in post-agricultural woodlands, while poor dispersers did not (Verheyen et al. 2003b, Kirkman et al. 2004, Vellend et al. 2007). Analysis of species' dispersal capacities warrants future work. However, agricultural environmental legacies may also restrict establishment of species typically associated with remnants into post-agricultural woodlands (Dupouey et al. 2002, Verheyen et al. 2003a, Flinn and Marks 2007). In this system, post-agricultural woodlands have lower soil moisture, soil organic matter, and inorganic nitrogen availability, but higher phosphorus and light available to the understory (Brudvig et al. 2013), all potentially important factors that could limit species establishment in postagricultural woodlands. Soil compaction is also higher in these post-agricultural woodlands (Brudvig et al. unpubl.), an environmental legacy that reduces the establishment of some species (Mattingly and Orrock 2013). Successful transplantation of remnant understory species into postagricultural longleaf pine woodlands suggests that environmental legacies are not strong enough to prevent the re-establishment of some species (Aschenbach et al. 2010). However, environmental conditions may reduce the spread of those or other species into post-agricultural woodlands by acting at earlier life stages. Either dispersal limitation or environmental conditions could explain the small-scale pattern of community similarity decay with distance from remnant woodlands, because both the likelihood of dispersal and environmental similarity decline with distance. Other types of establishment limitation, such as competition, herbivory, disease, mutualism, or other biotic interactions could also be at play. Further experimental work will be required to unequivocally show whether dispersal or environmental conditions, or both, or other types of establishment limitation, restrict the spread of species into post-agricultural woodlands (Brudvig et al. 2013).

We found no support for the hypothesis that agricultural legacies affect beta diversity in post-agricultural woodlands through homogenizing the environment at either large or small spatial scales. At within-site scales similar to this study, agricultural land-use can erode small-scale heterogeneity in some soil properties (Robertson et al. 1993, Fraterrigo et al. 2005, Flinn and Marks 2007), the opposite pattern to what we found. Fraterrigo et al. (2006) and Scheller and Mladenoff (2002) found that vegetation patterns were responsive to changes in environmental heterogeneity due to logging, but, like our study, Vellend et al. (2007) found no effect of a history of tillage on environmental heterogeneity. Further study will be 
required to resolve whether the environmental heterogeneity hypothesis is broadly important.

Effective biodiversity conservation in post-agricultural ecosystems depends on a mechanistic understanding of the constraints on community assembly. This study adds to a growing consensus that establishment limitation restricts the recovery of post-agricultural communities. Whether this limitation occurs through dispersal, the environment, altered biotic interactions, or other forces remains an important research question with relevance for land managers seeking to utilize post-agricultural ecosystems for conservation of rare and declining remnant-dependent species. Dispersal limitation is relatively easily overcome with seed addition or seedling transplants, but inhospitable environmental conditions such as reduced soil organic matter or persistent phosphorus legacies may be much more difficult to remedy. Altered biotic interactions, such as competition or mutualism, could also be difficult to manipulate on the landscape scales that are relevant to conservation.

This study also supports the role of establishment limitation for determining beta diversity. Furthermore, we build on previous work to show that establishment limitation can have counterintuitive effects on beta diversity at different spatial scales. The conservation implications of this finding are mixed. On one hand, the incomplete spread of remnant species into post-agricultural woodlands may facilitate some biodiversity conservation goals by increasing small-scale community heterogeneity and by promoting populations of remnant-associated species in post-agricultural areas through 'spillover' (Brudvig et al. 2009). On the other hand, conservation of remnant-associated species would likely benefit from further spread into post-agricultural woodlands. This lack of complete recolonization into post-agricultural woodlands suggests substantial remaining 'immigration credit' (Jackson and Sax 2010). Clarifying the multi-scale influences of establishment limitation will be essential for understanding these dynamics and for developing restoration strategies for assisting the recovery of post-agricultural communities.

Acknowledgements - We thank Chelsea Blake and Selina Pradhan for field and laboratory assistance and John Blake, Keith Lawrence, Ed Olson, and Kim Wright for logistical support. This work was supported by funds provided to the Dept of Agriculture, Forest Service, Savannah River, under Interagency Agreement DEAI09-00SR22188 with the Dept of Energy, Aiken, SC.

\section{References}

Alexander, H. M. et al. 2012. Metapopulations and metacommunities: combining spatial and temporal perspectives in plant ecology. - J. Ecol. 100: 88-103.

Anderson, M. J. et al. 2006. Multivariate dispersion as a measure of beta diversity. - Ecol. Lett. 9: 683-693.

Aschenbach, T. A. et al. 2010. The initial phase of a longleaf pine-wiregrass savanna restoration: species establishment and community responses. - Restor. Ecol. 18: 762-771.

Baeten, L. et al. 2010. Unexpected understorey community development after 30 years in ancient and post-agricultural forests. - J. Ecol. 98: 1447-1453.

Barton, P. S. et al. 2013. The spatial scaling of beta diversity. - Global Ecol. Biogeogr. 22: 639-647.
Brudvig, L. A. and Damschen, E. I. 2011. Land-use history, historical connectivity, and land management interact to determine longleaf pine woodland understory richness and composition. - Ecography 34: 257-266.

Brudvig, L. A. et al. 2009. Landscape connectivity promotes plant biodiversity spillover into non-target habitats. - Proc. Natl Acad. Sci. USA 106: 9328-9332.

Brudvig, L. A. et al. 2013. Strong legacies of agricultural land use on soils and understory plant communities in longleaf pine woodlands. - For. Ecol. Manage. 310: 944-955.

Chase, J. M. 2007. Drought mediates the importance of stochastic community assembly. - Proc. Natl Acad. Sci. USA 104: $17430-17434$.

Chase, J. M. et al. 2011. Using null models to disentangle variation in community dissimilarity from variation in alpha-diversity. - Ecosphere 2: art24.

Christensen, N. L. and Peet, R. K. 1984. Convergence during secondary succession. - J. Ecol. 72: 25-36.

Cramer, V. A. et al. 2008. What's new about old fields? Land abandonment and ecosystem assembly. - Trends Ecol. Evol. 23: 104-112.

del Moral, R. 2009. Increasing deterministic control of primary succession on Mount St. Helens, Washington. - J. Veg. Sci. 20: 1145-1154.

Dobson, A. P. et al. 1997. Hopes for the future: restoration ecology and conservation biology. - Science 277: 515-522.

Dupouey, J. L. et al. 2002. Irreversible impact of past land use on forest soils and biodiversity. - Ecology 83: 2978-2984.

Flinn, K. M. and Vellend, M. 2005. Recovery of forest plant communities in post-agricultural landscapes. - Front. Ecol. Environ. 3: 243-250.

Flinn, K. M. and Marks, P. L. 2007. Agricultural legacies in forest environments: tree communities, soil properties, and light availability. - Ecol. Appl. 17: 452-463.

Foster, B. L. et al. 2011. Seed availability constrains plant species sorting along a soil fertility gradient. - J. Ecol. 99: 473-481.

Fraterrigo, J. M. et al. 2005. Effects of past land use on spatial heterogeneity of soil nutrients in southern Appalachian forests. - Ecol. Monogr. 75: 215-230.

Fraterrigo, J. M. et al. 2006. Interactions between past land use, life-history traits and understory spatial heterogeneity. - Landscape Ecol. 21: 777-790.

Germain, R. M. et al. 2013. Spatial variability in plant predation determines the strength of stochastic community assembly. - Am. Nat. 182: 169-179.

Harrison, S. et al. 2011. "Structured" beta diversity increases with climatic productivity in a classic dataset. - Ecosphere 2: $\operatorname{art11.}$

Hiers, J. K. et al. 2007. Forest floor depth mediates understory vigor in xeric Pinus palustris ecosystems. - Ecol. Appl. 17: 806-814.

Jackson, S. T. and Sax, D. F. 2010. Balancing biodiversity in a changing environment: extinction debt, immigration credit and species turnover. - Trends Ecol. Evol. 25: 153-160.

Kirkman, L. K. et al. 2001. Productivity and species richness across an environmental gradient in a fire-dependent ecosystem. - Am. J. Bot. 88: 2119-2128.

Kirkman, L. K. et al. 2004. Ground cover recovery patterns and life-history traits: implications for restoration obstacles and opportunities in a species-rich savanna. - J. Ecol. 92: 409-421.

Kraft, N. J. B. et al. 2011. Disentangling the drivers of $\beta$ diversity along latitudinal and elevational gradients. - Science 333: 1755-1758.

Legendre, P. and Anderson, M. J. 1999. Distance-based redundancy analysis: testing multispecies responses in multifactorial ecological experiments. - Ecol. Monogr. 69: 1-24. 
Martin, L. M. et al. 2005. An assessment of grassland restoration success using species diversity components. - J. Appl. Ecol. 42: 327-336.

Matlack, G. R. 1994. Plant species migration in a mixed-history forest landscape in eastern North America. - Ecology 75: 1491-1502.

Mattingly, W. B. and Orrock, J. L. 2013. Historic land use influences contemporary establishment of invasive plant species. Oecologia 172: 1147-1157.

McLauchlan, K. 2006. The nature and longevity of agricultural impacts on soil carbon and nutrients: a review. - Ecosystems 9: 1364-1382.

Myers, J. A. and Harms, K. E. 2009. Local immigration, competition from dominant guilds, and the ecological assembly of high-diversity pine savannas. - Ecology 90: 2745-2754.

Myers, J. A. and Harms, K. E. 2011. Seed arrival and ecological filters interact to assemble high-diversity plant communities. - Ecology 92: 676-686.

Olden, J. D. and Rooney, T. P. 2006. On defining and quantifying biotic homogenization. - Global Ecol. Biogeogr. 15: 113-120.

Peet, R. K. 2006. Classification of longleaf pine woodlands. - In: Jose, S. et al. (eds), The longleaf pine ecosystem: ecology, silviculture, and restoration. Springer, pp. 51-93.

Plue, J. et al. 2008. Persistent changes in forest vegetation and seed bank 1,600 years after human occupation. - Landscape Ecol. 23: 673-688.

Polley, H. W. et al. 2005. Patterns of plant species diversity in remnant and restored tallgrass prairies. - Restor. Ecol. 13: 480-487.

Questad, E. J. et al. 2011. Evaluating patterns of biodiversity in managed grasslands using spatial turnover metrics. - Biol. Conserv. 144: 1050-1058.

Radford, A. E. et al. 1968. Manual of the vascular flora of the Carolinas. - Univ. North Carolina Press.

Robertson, G. P. et al. 1993. The spatial variability of soil resources following long-term disturbance. - Oecologia 96: 451-456.

Supplementary material (Appendix ECOG-01159 at < www. ecography.org/readers/appendix $>$ ). Appendix 1 .
Sala, O. E. et al. 2000. Global biodiversity scenarios for the year 2100. - Science 287: 1770-1774.

Scheller, R. M. and Mladenoff, D. J. 2002. Understory species patterns and diversity in old-growth and managed northern hardwood forests. - Ecol. Appl. 12: 1329-1343.

Singleton, R. et al. 2001. Forest herb colonization of postagricultural forests in central New York State, USA. - J. Ecol. 89: 325-338.

Standish, R. J. et al. 2007. Seed dispersal and recruitment limitation are barriers to native recolonization of old-fields in western Australia. - J. Appl. Ecol. 44: 435-445.

Veech, J. A. et al. 2002. The additive partitioning of species diversity: recent revival of an old idea. - Oikos 99: 3-9.

Veldman, J. W. et al. 2014. Fire frequency, agricultural history and the multivariate control of pine savanna understorey plant diversity. - J. Veg. Sci. doi: 10.1111/jvs. 12195

Vellend, M. et al. 2007. Homogenization of forest plant communities and weakening of species-environment relationships via agricultural land use. - J. Ecol. 95: 565-573.

Verheyen, K. and Hermy, M. 2001. The relative importance of dispersal limitation of vascular plants in secondary forest succession in Muizen Forest, Belgium. - J. Ecol. 89: 829-840.

Verheyen, K. and Hermy, M. 2004. Recruitment and growth of herb-layer species with different colonizing capacities in ancient and recent forests. - J. Veg. Sci. 15: 125-134.

Verheyen, K. et al. 2003a. An integrated analysis of the effects of past land use on forest herb colonization at the landscape scale. - J. Ecol. 91: 731-742.

Verheyen, K. et al. 2003b. Response of forest plant species to landuse change: a life-history trait-based approach. - J. Ecol. 91: 563-577.

Weakley, A. S. 2008. Flora of the Carolinas, Virginia, and Georgia, and surrounding areas. - Univ. of North Carolina Press.

Wilcove, D. S. et al. 1998. Quantifying threats to imperiled species in the United States. - Bioscience 48: 607-615. 